\title{
Territórios de inserção: questões de enquadre ${ }^{1}$
}

\section{Julio Frochtengarten ${ }^{2}$}

Meu território de inserção dentro da clínica psicanalítica é hoje, exclusivamente, o atendimento em consultório de clientes que atendo dentro da modalidade que se convencionou chamar hoje alta frequência. Será de dentro, e a partir, desta condição que pretendo abordar como penso o enquadre em psicanálise e suas variações. Espero que estas sejam questões que interessem e proporcionem conversa entre nós.

Em Freud não se encontra uma descrição ampla e geral do que poderíamos chamar de técnica analítica. Mesmo nos assim chamados "Artigos sobre Técnica" - 1911 a 1915 - não há uma exposição sistemática da técnica psicanalítica. Em um destes, ele esclarece que alcançou suas regras no decurso de muitos anos e pela própria experiência, enfatizando seu caráter individual:

Devo, contudo, tornar claro que o que estou asseverando é que esta técnica é a única apropriada à minha individualidade; não me arrisco a negar que um médico constituído de modo inteiramente diferente possa ver-se levado a adotar uma atitude diferente em relação a seus pacientes e à tarefa que se lhe apresenta (Freud, 1912/1969).

1 Este trabalho foi apresentado na mesa "Territórios de inserção: questões de enquadre " com Osvaldo Ferreira Leite no eixo "Psicanálise e suas clinicas" no I Simpósio Bienal "O mesmo, o outro: Psicanálise em movimento" da Sociedade Brasileira de Psicanálise de São Paulo. Este trabalho é uma versão atualizada e condensada de outro mais extenso publicado na Revista Brasileira de Psicanálise (Frochtengarten, 2010).

${ }^{2}$ Membro Efetivo e Analista Didata da Sociedade Brasileira de Psicanálise de São Paulo. 
Em vários destes artigos, Freud enfatiza que não descreve regras e sim recomendações. Não reivindica sua aceitação incondicional e as compara às recomendações dos manuais de xadrez:

Todo aquele que espere aprender o nobre jogo do xadrez nos livros, cedo descobrirá que somente as aberturas e os finais de jogo admitem uma apresentação sistemática exaustiva e que a infinita variedade de jogadas que se desenvolvem após a abertura desafia qualquer descrição deste tipo. Esta lacuna na instrução só pode ser preenchida por um estudo diligente dos jogos travados pelos mestres. As regras que podem ser estabelecidas para 0 exercício do tratamento psicanalítico acham-se sujeitas a limitações semelhantes (Freud, 1913/1969).

E continua:

A extraordinária diversidade das constelações psíquicas envolvidas, a plasticidade de todos os processos mentais e a riqueza dos fatores determinantes opõem-se a qualquer mecanização da técnica; e ocasionam que um curso de ação que, via de regra, é justificado possa, às vezes, mostrar-se ineficaz, enquanto outro que habitualmente é errôneo possa, de vez em quando, conduzir ao fim desejado. Essas circunstâncias, contudo, não nos impedem de estabelecer para o médico um procedimento que, em média, é eficaz. (Freud, 1913/1969).

É difícil reconstituir o caminho, mas todo este conjunto de considerações e recomendações escritas - muitas vezes examinadas em seus sentidos, significações e justificativas psíquicas acabaram por constituir o que hoje denominamos enquadre e setting. Elas dizem respeito a aspectos formais e às disposições do analista, incorporadas e encarnadas nele vindo a constituir o "palco" onde se espera que o encontro analítico possa acontecer.

No início de minha formação ouvia dizer que os termos enquadre e setting se referiam a algo interno ao analista e não aos aspectos formais da sala como neutralidade do ambiente criado no consultório, uso do divã, duração das sessões, horários estabelecidos, frequência, 
pagamentos, férias... Esta discriminação me fez sentido, adotei-a em teoria; e me parece haver certo consenso quanto a ela entre os analistas. Em minha prática cuido destes aspectos formais uma vez que eles me dão alguma estabilidade, mas percebo que não a garantem. Se os aspectos formais parecem importantes, é certamente a parte mais fácil de manter, enquanto este "algo interno" é bem mais difícil de ser definido, construído e mantido.

Não tenho como justificar, além de minha observação retroativa, minha opção em trabalhar, até aqui, dentro da modalidade em que venho praticando a psicanálise. Sei que este enquadre constitui e sustenta meu território de inserção, por me atender em termos de criar e estabelecer confiança, intimidade e liberdade com os clientes, tornando possível suportar as tensões e o esforço criativo inerente ao processo. Além do mais, lembrando que a psicanálise expande o próprio campo que investiga, encontro, em minha forma de trabalhar, uma boa condição para conter o que passa e o que vai surgindo nesse processo.

Em 2007 participei como convidado de uma Mesa no XXI Congresso Brasileiro de Psicanálise cujo tema era "Violações do Setting". Talvez hoje, apenas 11 anos depois, um debate sobre enquadre nem seria assim formulado e proposto... Apesar de minha estranheza já na ocasião, aceitei o convite e produzi um texto que denominei "É preciso ser psicanalista. $E$ preciso?” que foi publicado em 2010 na Revista Brasileira de Psicanálise (Frochtengarten, 2010). A apresentação continha uma ideia que até hoje mantenho para mim: o enquadre pode se instaurar e se manter desde que exista uma discriminação mínima de sujeito - objeto, presença - ausência, impulso - ação - eu e o outro. É esperado que esta condição mental esteja presente no analista; já o analisando é livre, não tem a priori compromisso com estas discriminações, a psicanálise ou seu setting. Enquadre é uma questão de responsabilidade ética do psicanalista - manter o vértice psicanalítico, sonhar e pensar dentro da turbulência emocional da sessão procurando integrar o "colorido do sentir ao preto e branco do pensar" (Cecilio, S. B., 2018).

Enquadre não é somente um conjunto de regras, mas sim referências, eixo, suporte ou ambiente no qual transcorre a análise. Deve estar, portanto, a serviço do método analítico, tornando-o celeiro de atividades psíquicas não conscientes. Variações do enquadre inicialmente proposto e ajustado entre mim e o cliente, quando ocorrem, deveriam ser 
compreendidas e pensadas dentro da experiência emocional que se dá neste vínculo. A parte fixa, formal, deste enquadre resultou de uma série de experiências que foram se configurando e consolidando a partir do próprio trabalho; e também de minhas exigências pessoais. Já, a parte mental dependerá da mobilidade dada pelas condições emocionais de ambos e do par a cada momento.

Assim, procuro instaurar o setting que escolho como suporte favorável à investigação que se inicia e sua elaboração consequente. Com esta convenção e referência estou comprometido até o limite em que - por minha conta e da dupla - me disponha a modifica-lo. Não vejo isso como violação, perturbação, interferência ou perigo; e sim como abertura para o outro com potencial riqueza comunicativa. Estas modificações se darão em função de minha disposição, meu grau de tolerância e capacidade de dar sentido e significado; ou, às vezes, de minha condição de suspender o significado e aguardar, me abrindo, com capacidade negativa, para a indagação.

Quando há condições de experimentar emoções e com elas desenvolver pensamentos em ambos os participantes da dupla - ou ao menos no analista - considero que está mantido um ambiente favorável à análise. Mas se, por exemplo, o analisando atribui ao mundo externo seja dentro ou fora da sala de análise - qualidades que são suas, através do chamado mecanismo de identificação projetiva - e o faz com excessiva crença - isto vai afetar intensamente o ambiente da análise. Em situação assim o universo mental pode sofrer expansão de tal magnitude que não é mais visto como pertinente ao âmbito psíquico, nem à relação com o analista na sala. $\mathrm{O}$ ambiente analítico sofre modificação explosiva, expandindose para o infinito e ameaçando a possibilidade da análise. Se o analista tem o método analítico internalizado, se tem compromisso e disposição consistentes em favorecer a análise, modifica o setting sem sentir-se sob pressão da parte cindida, projetada, não pensada do cliente; se percebe, no momento ou atrasado, ter decidido sob pressão e não com autonomia, cabe a ele abrigar o que antes não pode ser pensado. Isto é uma decisão que cada analista tomará a cada momento. O compromisso do analista não é com o setting convencionado, mas sim com a ética de favorecer crescimento. 
Questões de enquadre, o título desta Mesa, para mim se confunde com o próprio método analítico. É, por excelência, a disposição para examinar, estando dentro, as emoções presentes e seus movimentos no decorrer do tempo. "O setting pode ser considerado como claustro (Meltzer, 1992) ou como continente com qualidades de elasticidade e robustez (Bion, 1962)" (Ferro, 1998).

Enquanto meu cliente se move como e por onde pode, é útil que possa encontrar em mim o analista encarnado. Assim, aquilo que começa como convenção pode direcionar o contato para a sondagem de nossas dimensões emocional e psíquica.

Penso em setting como um conjunto de condições que me favorecem exercer psicanálise, incluindo aí momentos em que o setting convencional é mantido e outros em que o modifico. Também estão incluídos neste conjunto o sentido e significação psíquica que sustentam esta manutenção ou mudança: por ação super-egóica ou egóica, por pensamento ou automatismo? É neste ambiente de indagações que vou trabalhando, em relação como ser humano com outro.

$\mathrm{Na}$ mente humana - não é demais lembrar que isto vale para analistas e analisandos predomina o sistema não consciente, território do infinito incognoscível e inefável. A mente, por sua natureza e modo de funcionar, por si própria não cabe em enquadres, podendo expandir-se até o infinito como se evidencia, por exemplo, nas alucinoses. Cito Bion: "A situação do psicanalista lidando com transformações psicóticas é similar àquela atribuída aos físicos nucleares. Eles têm que lidar com relacionamentos de um domínio que não tem limitações finitas" (Bion, 1983).

Em outras palavras, o que chamamos mente, e queremos conhecer e lidar com ela, não se mantém limitada pela simples demanda de uma organização externa fixa e estruturada. Preciso disciplina para me servir do método analítico; isso inclui um campo delimitado que devo decidir e escolher em meu trabalho. Colocar-se dentro dele não é, por si só, uma forma do ser humano operar; é tão somente uma possibilidade que depende da capacidade do momento de pensar nas, e com, as experiências emocionais vividas. O pensamento permite 
diferenciações, discriminações, diferenças e semelhanças; já o não-pensamento homogeneíza, apaga as diferenças, padroniza. Como a experiência analítica envolve tanto pensamento quanto não-pensamento, preciso sempre que possível investigar o sentido e a significação de atender a cada aspecto do enquadre proposto. Lembro mais uma vez que este é um compromisso do analista com seu próprio pensamento e a psicanálise - seu método e sua ética.

É assim que procuro estar presente na sala e no momento. Isto envolve a difícil disciplina de escapar do passado e do futuro e, sensível ao maior número de fenômenos, estar disponível para o que não é conhecido, num processo alheio às contradições, à lógica, às sequencias e à causalidade, em ambiente propício para que possam surgir fatos selecionados (Bion, 1966) que dão coerência e significado a eventos conhecidos. Este processo vai me dando uma direção, uma possibilidade de dizer algo ao paciente, "criando" um interlocutor para mim. Com isso espero estar deixando claro que entendo a prática da psicanálise como um processo; este não se confunde com outras modalidades práticas que implicam em intervenções pontuais que possam estar inspiradas na teoria e clínica psicanalítica.

Pelas dificuldades inerentes à tarefa podemos ficar tentados a transformar o setting, originalmente condição para o trabalho analítico, em substituto da psicanálise. Psicanálise e setting psicanalítico - em seus aspectos formais - não podem ser confundidos um com o outro. Somente a preservação do método analítico, nutrindo o desenvolvimento de um processo e da capacidade de pensar dos analistas, pode afastar a ameaça de dispersão e confusão na psicanálise, respeitando a diversidade psíquica e cultural da raça humana.

Há um provérbio latino que diz: "O que é rígido desaba e o que está em constante movimento persiste".

\section{Referências}

Bion, W.R. (1966). Elementos de Psicanálise. Rio de Janeiro: Imago, p. 153. (Trabalho original publicado em 1963) 
(1983). Transformações. Rio de Janeiro: Imago, p.62. (Trabalho original publicado em 1965).

Cecilio, S. B. (2018). Integrando \& Diferenciando - Matemática \& Psicanálise.Minas Gerais: Edição da Autora, p. 94.

Ferro, A. (1998). Na sala de análise. Rio de Janeiro: Imago.

Freud, S (1969). Recomendações aos médicos que exercem psicanálise. In: Edição Standard Brasileira das Obras Psicológicas Completas de Sigmund Freud (J. Salomão, trad., Vol XII, p. 149). Rio de Janeiro: Imago. (Trabalho original publicado em 1912).

(1969). Sobre o início do tratamento (Novas recomendações sobre a técnica da psicanálise I). In: Edição Standard Brasileira das Obras Psicológicas Completas de Sigmund Freud (J. Salomão, trad., Vol XII, p. 164). Rio de Janeiro: Imago. (Trabalho original publicado em 1913).

Frochtengarten, J. (2007). Ver. Bras. Psicanál, 2010, v.44, nº 2, p.45-53. 